\title{
Multicentre Covariate Adjustment Analysis of Short-Term and 5-Year Outcomes after Endovascular Repair according to Sex
}

\author{
Bibombe P. Mwipatayi $\left(\mathbb{D},{ }^{1,2,3}\right.$ Rebekah L.W Tan, ${ }^{1}$ Joseph Faraj ${ }^{(D},{ }^{1}$ Ali Daneshmand, ${ }^{1}$ \\ Olufemi Oshin, ${ }^{1}$ Nishath Altaf $\left(\mathbb{0},{ }^{1}\right.$ Shannon D. Thomas, ${ }^{4,5,6}$ Patrik J Tosenovsky, ${ }^{1}$ \\ Jackie Wong, ${ }^{3}$ Vikram Vijayan, ${ }^{7}$ Anthony J. Freeman, ${ }^{8}$ and Sally A. Burrows $\oplus^{9}$ \\ ${ }^{1}$ Department of Vascular Surgery, Royal Perth Hospital, Perth, WA, Australia \\ ${ }^{2}$ Faculty of Medicine, Dentistry and Health Sciences, University of Western Australia, Perth, WA, Australia \\ ${ }^{3}$ Perth Institute of Vascular Research, Perth, WA, Australia \\ ${ }^{4}$ Department of Vascular Surgery, Prince of Wales Hospital, Sydney, NSW, Australia \\ ${ }^{5}$ Faculty of Medicine, University of New South Wales, Sydney, NSW, Australia \\ ${ }^{6}$ The Vascular Institute, Prince of Wales Hospital, Sydney, NSW, Australia \\ ${ }^{7}$ Vascular Diagnostic Laboratory, Ng Teng Fong General Hospital, Singapore \\ ${ }^{8}$ Faculty of Medicine and Health, University of Sydney, Sydney, NSW, Australia \\ ${ }^{9}$ School of Medicine, University of Western Australia, Perth, WA, Australia
}

Correspondence should be addressed to Bibombe P. Mwipatayi; bibombe@iinet.net.au

Received 5 June 2019; Accepted 4 February 2020; Published 9 March 2020

Academic Editor: Cosimo Sperti

Copyright ( 12020 Bibombe P. Mwipatayi et al. This is an open access article distributed under the Creative Commons Attribution License, which permits unrestricted use, distribution, and reproduction in any medium, provided the original work is properly cited.

\begin{abstract}
Background. Several studies have reported worse outcomes in women compared to men after endovascular aneurysm repair (EVAR). This study aimed to evaluate sex-specific short-term and 5-year outcomes after EVAR. Methods. A total of 409 consecutive patients underwent elective EVAR from 2004 to 2017 at two tertiary hospitals in Western Australia. Baseline, intraoperative, and postoperative variables were examined retrospectively according to sex. The primary outcome was 30-day mortality (death within 30 days after EVAR). Secondary outcomes were 30-day composite endpoint, length of stay after EVAR, 5year survival, freedom from reintervention, residual aneurysm size after EVAR, and major adverse event rate at 5-year follow-up. Results. A cohort of 409 patients, comprising 57 women (14\%) and 352 men (86\%), was analysed. Female patients were older (median age, 76.8 versus 73.5 years, $p=0.017$ ). Male patients were more likely to be past smokers ( $40.9 \%$ versus $22.8 \%, p=0.005$ ) and have a history of coronary artery bypass grafting $(11.2 \%$ versus $3.5 \%, p=0.042)$ and malignancy $(24.1 \%$ versus $10.5 \%$, $p=0.014)$. No difference in 30-day mortality or composite endpoints was demonstrated for female patients compared with male patients (3.5\% versus $0.3 \%, p=0.052$ and $31.6 \%$ versus $27.8 \%, p=0.562$, respectively). The Kaplan-Meier curves demonstrated similar 5-year mortality outcomes amongst male and female patients $(p=0.928)$. Long-term survival analysis adjusting for covariates demonstrated no significant difference in long-term mortality, composite endpoints, and reintervention rate between sexes. Conclusion. This study found no significant differences in 30-day and 5-year outcomes between female and male patients treated with EVAR, implying that EVAR remains a safe treatment choice for female patients.
\end{abstract}

\section{Introduction}

There is a higher prevalence of abdominal aortic aneurysms (AAA) in men than in women, with a $4: 1$ male predominance [1]. Intervention is usually offered when the aneurysm diameter has reached $5.5 \mathrm{~cm}$ or if the aneurysm is symptomatic.
This consensus on size was established through various randomised controlled trials, wherein women were mostly underrepresented $[2,3]$.

Compared to men, women are often diagnosed at a later age, have a faster rate of aneurysm growth, a fourfold higher risk of rupture, and a higher risk of rupture at a smaller AAA 
diameter, and are three times more likely to die following the rupture of an aneurysm [4,5]. Differences in pathophysiology, presentation, and outcomes following repair of AAA have been reported between sexes, rendering it difficult to identify the optimal threshold for treatment [6-8].

Endovascular aneurysm repair (EVAR) is increasingly performed as an alternative to open repair. EVAR is a minimally invasive treatment option for those deemed unfit for open surgery [9]. It is also associated with shorter hospital stays and reduced short-term mortality [9]; however, this benefit may not be the case in female patients who demonstrate a three-fold increase in mortality following elective EVAR compared to their male counterparts $[10,11]$.

The difference in these outcomes is poorly understood; however, several explanations have been postulated. Women tend to present at a more advanced age and more often with undiagnosed and untreated comorbidities that may increase their perioperative risk $[1,4]$. In addition, women have been shown to have more adverse infrarenal and iliac anatomy that is associated with higher procedural complication rates, such as endoleak, abandonment of procedure, conversion to open surgery, and need reintervention $[4,6,10]$. Female patients also represent a minority of EVAR recipients in most trials; hence, our knowledge on EVAR and improvements made to operative devices are inherently based more on the male population. As such, the current AAA management guidelines are predominantly based on outcomes in male patients, and whether these outcomes should guide management in female patients is controversial. In this study, we sought to investigate the relationship between sex and outcomes following EVAR.

\section{Methods}

This is a retrospective study based on a prospectively collected database. The study subjects comprise all patients treated electively with an endovascular aortic repair for an AAA, at two major Western Australian hospitals, between January 2004 and December 2017. Patient data were retrieved from the hospital's electronic database and medical records where patients were followed in hospital clinics. Further, preoperative and control CTAs, angiographic findings, and ultrasound data were reanalysed. Patient inclusion criteria were age $>18$ years and indication for elective repair of AAA with an endovascular stent graft in accordance with the guidelines on endovascular aneurysm repair. Patients who had undergone thoracic endovascular aortic repair were excluded.

Baseline data including comorbidities were collected and stored in an electronic worksheet (Microsoft Excel, Palo Alto, CA). The primary outcome was 30-day mortality, defined as death within 30 days of the index EVAR. Secondary outcomes were 30-day composite endpoint (local and systemic complications, conversion to open repair, and occurrence of endoleak), length of stay (LOS) after EVAR between both groups, 5-year survival between both groups, freedom from reintervention at 5-years follow-up, residual aneurysm size after EVAR at 5-years follow-up, and major adverse event (MAE) rate at 5-years follow-up. Technical factors were also analysed, such as successful delivery and deployment of the stent graft in the absence of stent graft malfunction, kinking/twisting, or fracture. Information at follow-up visits $(1,3,6,12$, and yearly thereafter) was recorded on a standardised electronic case record form.

MAEs were defined as either death or interventions including conversion to open repair, aneurysm rupture, major embolic event, graft infection requiring explanation, device migration, loss of device patency requiring reintervention, wound infection, and other complications (including cardiovascular, pulmonary, renal, gastrointestinal, and neurological complications). Device migration was reported if it required intervention or if an adequate seal was lost, usually when reduced to $<10 \mathrm{~mm}$ of the circumferential apposition length. This study received ethical approval from the ethics committee of each institution. Informed consent was not sought as anonymised patient data were used.

2.1. Statistical Analysis. Counts and percentages, means and standard deviations or medians, and first to third quartiles [Q1, Q3] were used to summarise data. Differences in patient demographics and anatomical characteristics between male and female patients were tested using chi-square or Fisher's exact test for categorical characteristics; $t$-tests or Wilcoxon rank sum tests were used for continuous characteristics.

Differences in mortality and MAEs between male and female patients were investigated initially using univariate logistic regression. Multivariable logistic regressions were then performed on 5-year outcomes to adjust for age, American Society of Anesthesiologists classification, comorbidities, hospital, stent type, and AAA characteristics, and bootstrapped to ensure that $p$ values were robust to overfitting. A variance adjustment was applied to the regression models to account for clustering of patients within treating surgeons. Further, inverse probabilityweighted analysis with a regression adjustment (propensity score) was performed to avoid overfitting. A propensity score model was tested in the assumption of overlap that everyone in the study had a positive probability of receiving each treatment level equally, but this suggested that the overlap assumption was not violated. This was more robust because it weighted the analysis using the propensity score in addition to the regression adjustment (Figure 1).

A Kaplan-Meier curve was generated to illustrate the unadjusted long-term survival function for male and female patients and differences tested using the log-rank test. Differences in hospital LOS were analysed using truncated negative binomial regressions due to the count nature of the outcome and skewness present. All analyses were performed using Stata 15 (StataCorp. 2017. Stata Statistical Software: Release 15. College Station, TX: StataCorp LLC), and significance was set at $p<0.05$. 


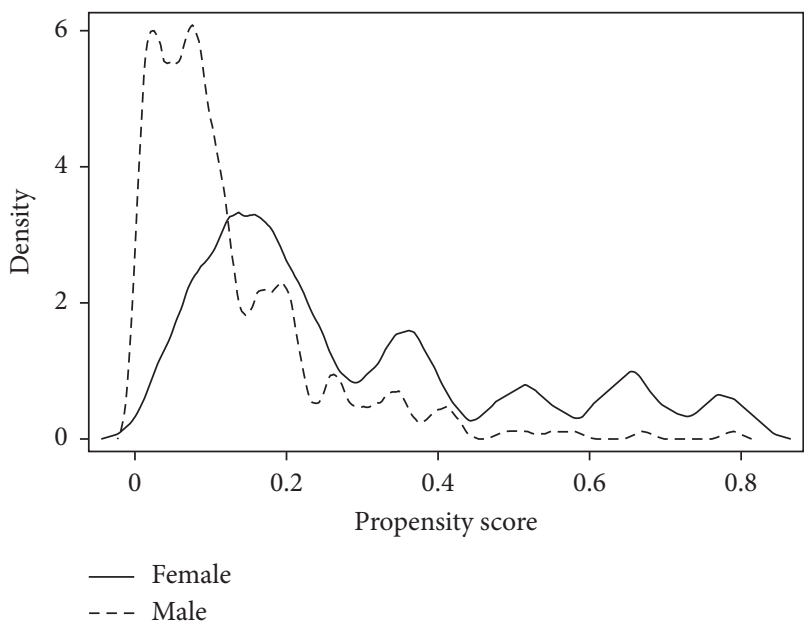

FIgURE 1: Propensity score model testing the assumption of overlap that each individual has a positive probability of receiving each treatment level.

\section{Results}

From 2004 to 2017, 409 patients (57 women and 352 men) underwent elective EVAR. Baseline demographics and clinical characteristics are listed and compared in Table 1. During intervention, women were significantly older than men (mean age, 76.8 years versus 73.5 years, $p=0.017$ ). Most patients, regardless of sex, were Caucasian. Male patients were significantly more likely to be past smokers ( $40.9 \%$ versus $22.8 \%, p=0.005$ ), have a history of coronary artery bypass grafting (CABG) (11.2\% versus $3.5 \%$, $p=0.042)$, and have a history of malignancy compared with their female counterparts $(24.1 \%$ versus $10.5 \%, p=0.014)$. No other significant differences in comorbidities or baseline characteristics were detected between sexes.

3.1. Anatomical Characteristics. The stent graft type is listed in Table 1. No statistical difference in device selection was found between the sexes. Anatomical details are summarised in Table 2. Whilst female patients had smaller infrarenal aortic neck angles $\left(14.0^{\circ}\right.$ versus $\left.20.2^{\circ}, p=0.041\right)$ compared to that in men, no significant differences in aneurysmal sac diameter, length of infrarenal aortic neck, and the length of the aneurysm were noted between sexes. Neck calcification, thrombus load, and distal common iliac artery diameter did not reach a statistically significant difference between sexes.

3.2. Perioperative Outcomes. No significant differences in the average length of postoperative hospital or intensive care stays were observed between sexes (Table 3). No differences were found in technical success (98.2\% versus $98.6 \%$, $p=0.597)$, freedom from intraoperative death $(100 \%$ both groups), and freedom from type I endoleak (0.00\% versus $0.85 \%)$. However, type II and III endoleaks were higher in male patients than in female patients $(10.8 \%$ versus $7.0 \%$ and $0.0 \%$ versus $0.6 \%$, respectively); nonetheless, these differences were not statistically significant between sexes. The
Table 1: Patient demographics.

\begin{tabular}{|c|c|c|c|}
\hline Characteristic & $\begin{array}{l}\text { Females } \\
(n=57)\end{array}$ & $\begin{array}{c}\text { Males } \\
(n=352)\end{array}$ & $\begin{array}{c}p \\
\text { value }\end{array}$ \\
\hline Age, years & $76.8 \pm 9.5$ & $73.5 \pm 9.8$ & 0.017 \\
\hline $\mathrm{BMI}>30$ & $9(15.8 \%)$ & $94(26.7 \%)$ & 0.066 \\
\hline Ethnicity & & & 0.243 \\
\hline Caucasian & $52(92.8 \%)$ & $347(98.6 \%)$ & \\
\hline Asian & - & $4(1.1 \%)$ & \\
\hline African & - & - & \\
\hline Maori & - & - & \\
\hline ATSI & $4(7.1 \%)$ & - & \\
\hline Others & - & $1(0.3 \%)$ & \\
\hline \multicolumn{4}{|l|}{ Comorbidities } \\
\hline \multicolumn{4}{|l|}{ Smoking } \\
\hline Current & $24(42.11 \%)$ & $146(41.5 \%)$ & 0.929 \\
\hline Former & $13(22.8 \%)$ & $143(40.9 \%)$ & 0.005 \\
\hline Hypertension & $41(71.9 \%)$ & $269(76.6 \%)$ & 0.447 \\
\hline Hyperlipidaemia & $28(50 \%)$ & $177(52.4 \%)$ & 0.743 \\
\hline Diabetes & $12(21.0 \%)$ & $84(23.9 \%)$ & 0.639 \\
\hline Cardiac & $34(59.6 \%)$ & $177(50.3 \%)$ & 0.188 \\
\hline Angina & $10(17.5 \%)$ & $60(17.0 \%)$ & 0.926 \\
\hline Arrhythmia & $8(14.0 \%)$ & $62(17.6)$ & 0.496 \\
\hline CABG & $2(3.5 \%)$ & $40(11.2 \%)$ & 0.042 \\
\hline CAS & $3(5.3 \%)$ & $24(6.8 \%)$ & 0.652 \\
\hline $\mathrm{CHF}$ & $2(3.5 \%)$ & $27(7.7 \%)$ & 0.215 \\
\hline MI & $7(12.5 \%)$ & $53(15.2 \%)$ & 0.592 \\
\hline Renal & $5(8.8 \%)$ & $57(16.2 \%)$ & 0.124 \\
\hline \multicolumn{4}{|l|}{ Carotid } \\
\hline CVA & $7(12.3 \%)$ & $35(10.0 \%)$ & 0.598 \\
\hline TIA & $5(8.8 \%)$ & $28(7.9 \%)$ & 0.835 \\
\hline PVD & $13(22.8 \%)$ & $94(26.7 \%)$ & 0.529 \\
\hline COPD & $14(24.6 \%)$ & $98(27.8 \%)$ & 0.603 \\
\hline $\begin{array}{l}\text { History of } \\
\text { malignancy }\end{array}$ & $6(10.5 \%)$ & $85(24.1 \%)$ & 0.014 \\
\hline ASA classification & & & 0.445 \\
\hline Class I & 1 & 3 & \\
\hline Class II & 12 & 75 & \\
\hline Class III & 38 & 209 & \\
\hline Class IV & 6 & 64 & \\
\hline Stent type & & & 0.764 \\
\hline 1 Endurant & $22(38.6 \%)$ & $159(45.4 \%)$ & \\
\hline 2 Cook Zenith & $3(5.3 \%)$ & $28(8 \%)$ & \\
\hline 3 Gore Excluder & $9(15.8 \%)$ & $56(16 \%)$ & \\
\hline 4 Nellix $^{\circledR} /$ AFX & $3(5.3 \%)$ & $17(4.9 \%)$ & \\
\hline 5 Talent & $7(12.3 \%)$ & $33(9.4 \%)$ & \\
\hline 6 Complex EVAR & $13(22.8 \%)$ & $57(16.3 \%)$ & \\
\hline \multicolumn{4}{|l|}{ Hospital } \\
\hline Public & & & 0.116 \\
\hline
\end{tabular}

Note. BMI: body mass index; ATSI: Aboriginal or Torres Strait Islander; CABG: coronary artery bypass grafting; CAS: coronary artery stenting; CHF: chronic heart failure; MI: myocardial infarction; CVA: cerebrovascular accident; TIA: transient ischaemic attack; PVD: peripheral vascular disease; COPD: chronic obstructive pulmonary disease; ASA: American Society of Anesthesiologists classification; Nellix ${ }^{\circledR}$ : endovascular aneurysm sealing system.

estimated all-cause mortality rates at 30 days were $3.5 \%$ $(n=2)$ in women and $0.3 \%(n=1)$ in men $(p=0.052)$.

Complications occurring following surgery are shown in Table 3. Complication rates were slightly higher in female than in male patients, that is, cardiovascular events at $10.5 \%$ versus $7.7 \%$, groin wound haematoma at $8.8 \%$ versus $4.8 \%$, and wound infection at $5.3 \%$ versus $2.3 \%$; conversely, access vessel complications, postoperative gastrointestinal bleeding, 
TABle 2: Anatomical characteristics.

\begin{tabular}{|c|c|c|c|}
\hline Characteristics & Females $(n=57)$ & Males $(n=352)$ & $p$ value \\
\hline Size of aneurysm $(\mathrm{mm})$ & $56.3 \pm 9.9$ & $59.7 \pm 13.3$ & 0.082 \\
\hline Length of infrarenal neck ( $\mathrm{mm})$ & $29.3 \pm 8.8$ & $32.3 \pm 13.1$ & 0.191 \\
\hline Proximal neck diameter $(\mathrm{mm})$ & $24.0 \pm 3.2$ & $24.1 \pm 2.8$ & 0.799 \\
\hline Distal neck diameter (mm) & $27.3 \pm 2.7$ & $26.7 \pm 2.9$ & 0.112 \\
\hline Neck angulation $\left({ }^{\circ}\right)$ & $14.0 \pm 15.7$ & $20.2 \pm 20.4$ & 0.041 \\
\hline Neck angulation $>60^{\circ}$ & $2(3.5 \%)$ & $35(9.9 \%)$ & 0.081 \\
\hline Neck flaring $>1 \mathrm{~mm}$ & $27(47.4 \%)$ & $140(39.8 \%)$ & 0.282 \\
\hline Neck thrombosis & & & 0.566 \\
\hline None & $36(63.2 \%)$ & $215(61.0 \%)$ & \\
\hline Mild & $14(24.6 \%)$ & $109(31.0 \%)$ & \\
\hline Moderate & $6(10.5 \%)$ & $26(7.4 \%)$ & \\
\hline Severe & $1(1.7 \%)$ & $2(0.6 \%)$ & \\
\hline Length of infrarenal aorta $(\mathrm{mm})$ & $117.9 \pm 10.8$ & $121.6 \pm 13.9$ & 0.289 \\
\hline Right CIA length $(\mathrm{mm})$ & $59.8 \pm 11.3$ & $61.9 \pm 12.8$ & 0.237 \\
\hline Distal right CIA diameter $(\mathrm{mm})$ & $14.5 \pm 6.6$ & $15.3 \pm 7.5$ & 0.259 \\
\hline Right EIA diameter $(\mathrm{mm})$ & $9.3 \pm 1.3$ & $9.6 \pm 1.4$ & 0.113 \\
\hline Right iliac tortuosity & & & 0.423 \\
\hline None & $35(61.4 \%)$ & $183(52.0 \%)$ & \\
\hline Mild & $7(12.3 \%)$ & $61(17.3 \%)$ & \\
\hline Moderate & $12(21.0 \%)$ & $74(21.0 \%)$ & \\
\hline Severe & $3(5.3 \%)$ & $34(9.7 \%)$ & \\
\hline Left CIA length (mm) & $56.7 \pm 10.7$ & $57.1 \pm 8.8$ & 0.139 \\
\hline Distal left CIA diameter (mm) & $13.6 \pm 2.6$ & $13.8 \pm 2.9$ & 0.456 \\
\hline Left EIA diameter $(\mathrm{mm})$ & $9.6 \pm 1.5$ & $9.8 \pm 1.4$ & 0.285 \\
\hline Left iliac tortuosity & & & 0.650 \\
\hline None & $29(50.9 \%)$ & $156(44.3 \%)$ & \\
\hline Mild & $14(24.6 \%)$ & $104(29.5 \%)$ & \\
\hline Moderate & $12(21.0 \%)$ & $70(19.9 \%)$ & \\
\hline Severe & $2(3.5 \%)$ & $22(6.2 \%)$ & \\
\hline Neck calcification & & & 0.459 \\
\hline None & $43(75.4 \%)$ & $278(79.0 \%)$ & \\
\hline Mild to moderate & $12(21.05 \%)$ & $70(19.9 \%)$ & \\
\hline Severe & $2(3.5 \%)$ & $4(1.1 \%)$ & \\
\hline Patent lumbar vessels & $51(89.5 \%)$ & $292(82.9 \%)$ & 0.193 \\
\hline Patent IMA & $49(86.0 \%)$ & $286(81.2 \%)$ & 0.378 \\
\hline Patent left iliac & $51(89.5 \%)$ & $333(94.6 \%)$ & 0.164 \\
\hline Patent right iliac & $53(93.0 \%)$ & $326(92.6 \%)$ & 0.921 \\
\hline
\end{tabular}

Note. CIA: common iliac artery; EIA: external iliac artery; IMA: inferior mesenteric artery.

ischaemic colitis, and neurological accidents were more observed in men than in women. However, none of these differences were statistically significant between sexes.

3.3. Late Outcomes. MAEs occurred in 20 (35.7\%) women and in $123(35.5 \%)$ men $(p=0.981)$. At 5 years, $35(87.5 \%)$ women and $222(88.8 \%)$ men were free from arterial reinterventions $(p=0.812)$. No significant difference was found in unadjusted long-term mortality between male and female patients (15 (26.8\%) versus 95 (27.5\%), $p=0.907$; odds ratio $(\mathrm{OR})=1.04 ; 95 \%$ confidence interval $(\mathrm{CI})$, 0.53-2.02) which was also reflected in the Kaplan-Meier survival curve (log-rank test $p=0.928$ ) (Figure 2). Residual aneurysmal size assessed by ultrasonography did not differ significantly between the two groups $(51.2 \mathrm{~mm}$ versus $53.2 \mathrm{~mm}, p=1.000)$.

The multivariate logistic regression demonstrated no difference in 5-year mortality for women compared with men (OR 1.07; 95\% CI, 0.44-2.94; $p=0.81$ ) nor for the composite of mortality and MAEs at 5 years (OR 1.04; 95\% CI, 0.93-1.18; $p=0.6$ ) (Table 4).

\section{Discussion}

This study found no difference in the short-term and longterm mortality and morbidity between male and female patients who underwent EVAR. This result supports findings from several series which acknowledge that, despite some differences in baseline characteristics between men and women, similar perioperative mortality and survival benefit exist; thus, EVAR should be recommended to suitable candidates regardless of their sex [12]. Contrary to this, other studies show that female patients have not experienced the same degree of positive outcomes after EVAR that male patients have had due to anatomical and biologic differences, delayed presentation, and under-representation in clinical trials [13, 14]. Grootenboer et al.'s [15] article based on the EUROSTAR registry demonstrated no difference in 30-day mortality between male and female patients, but significantly 
TABLe 3: Perioperative data, 30-day, and long-term outcomes.

\begin{tabular}{|c|c|c|c|}
\hline & Females $(n=57)$ & Males $(n=352)$ & $p$ value \\
\hline Type of anaesthesia & & & 0.725 \\
\hline Local/regional & $16(28.1 \%)$ & $91(25.9 \%)$ & \\
\hline General & $41(71.9 \%)$ & $261(74.1 \%)$ & \\
\hline Length of stay (days) & $6(4,9)$ & $4(3,7)$ & 0.279 \\
\hline Length of ICU stay (days) & $1(1,2)$ & $1(1,2)$ & 0.896 \\
\hline \multicolumn{4}{|l|}{ Intraoperative } \\
\hline Successful deployment & $56(98.2 \%)$ & $346(98.6 \%)$ & 0.597 \\
\hline Death & - & - & \\
\hline Rupture & - & $5(1.4 \%)$ & 1.000 \\
\hline Conversion to open & $1(1.8 \%)$ & $4(1.1 \%)$ & 0.530 \\
\hline \multicolumn{4}{|l|}{ Endoleak } \\
\hline Type I & - & $3(0.85 \%)$ & 1.000 \\
\hline Type II & $4(7.0 \%)$ & $38(10.8 \%)$ & 0.362 \\
\hline Type III & - & $2(0.6 \%)$ & 1.000 \\
\hline Type IV & - & $1(0.3 \%)$ & 1.000 \\
\hline \multicolumn{4}{|l|}{ From operation to discharge } \\
\hline Wound infection & $3(5.3 \%)$ & $8(2.3 \%)$ & 0.187 \\
\hline Seroma & $1(1.7 \%)$ & $7(2.0 \%)$ & 1.000 \\
\hline Haematoma & $5(8.8 \%)$ & $17(4.8 \%)$ & 0.253 \\
\hline Access vessel dissection & - & $4(1.1 \%)$ & 1.000 \\
\hline False aneurysm & - & $3(0.8 \%)$ & 1.000 \\
\hline Distal vessel embolization & - & $2(0.6 \%)$ & 1.000 \\
\hline Ischaemic limb & $1(1.7 \%)$ & $4(1.1 \%)$ & 0.530 \\
\hline Ischaemic colitis & - & $1(0.3 \%)$ & 1.000 \\
\hline CVS & $6(10.5 \%)$ & $27(7.7 \%)$ & 0.478 \\
\hline Pulmonary & $1(1.7 \%)$ & $12(3.4 \%)$ & 1.000 \\
\hline Renal & $3(5.3 \%)$ & $19(5.4 \%)$ & 0.967 \\
\hline GI bleed & - & $2(0.6 \%)$ & 1.000 \\
\hline CNS & - & $3(0.8 \%)$ & 1.000 \\
\hline \multicolumn{4}{|l|}{ 30-day mortality } \\
\hline All cause & $2(3.5 \%)$ & $1(0.3 \%)$ & 0.052 \\
\hline \multicolumn{4}{|l|}{ 30-day composite outcome } \\
\hline Complications and mortality & $18(31.6 \%)$ & $98(27.8 \%)$ & 0.562 \\
\hline \multicolumn{4}{|l|}{ Long-term outcomes at 5 years } \\
\hline All-cause mortality & $15(26.8 \%)$ & $95(27.5 \%)$ & 0.907 \\
\hline Freedom from reintervention & $35(87.5 \%)$ & $222(88.8 \%)$ & 0.812 \\
\hline MAE rate & $20(35.7 \%)$ & $123(35.5 \%)$ & 0.981 \\
\hline Residual aneurysm size $(\mathrm{mm})^{\dagger}$ & $51.2 \pm 17.2$ & $53.2 \pm 16.4$ & 1.000 \\
\hline
\end{tabular}

Note. ICU: intensive care unit; CVS: cardiovascular system; CNS: central nervous system; MAE: major adverse events. ${ }^{\dagger} 5$ women and 51 men had residual aneurysm.

higher cumulative incidence of the composite endpoint mortality, systemic complications, or conversion (OR 1.32, 95\% CI 1.05-1.66). In their survival analysis, even after adjusting for covariates, they also demonstrated a statistically significant higher rate of composite endpoint mortality and reintervention (hazard risk ratio 1.28, 95\% CI $1.07-1.54)$. Women represented $7.2 \%$ of their cohort.

Our study contributes to the current literature as it demonstrates outcomes for a relatively large cohort of patients in two major tertiary centres in Western Australia. As such, the results are representative of the contemporary population treated in this region. The cohort studied is also comparable to those studied in previous literature: (i) the proportion of female patients in our study (16.2\%) parallels that quoted in the literature (range $7.8 \%-21.6 \%$ ) $[16,17]$ and (ii) the finding that female patients who undergo elective EVAR are older than male patients is also a consistent finding with previous literature (age range $73-78$ years) $[13,16,17]$.
Several factors contributed to why female patients present at an older age for aortic aneurysm repair. First, women are less likely to have imaging that may detect AAA either intentionally or incidentally. Most AAA screening programmes do not include women; for example, the United Kingdom aortic aneurysm screening programme only includes men age $>65$ years. No formal AAA screening guidelines or programs exist currently in Australia [14, 18]. The lack of incidental imaging of the aorta could also relate to either women having fewer comorbidities or undergoing fewer investigation for their comorbidities. Another reason to AAA being diagnosed later in women may be attributed to the loss of oestrogen, which is postulated to be protective against aneurysm development for women in their earlier reproductive years. This protection may be eliminated after menopause $[15,19]$. This means that the disease process starts later in life among women, hence delaying their presentation; thus, repair is performed at a more advanced age. 


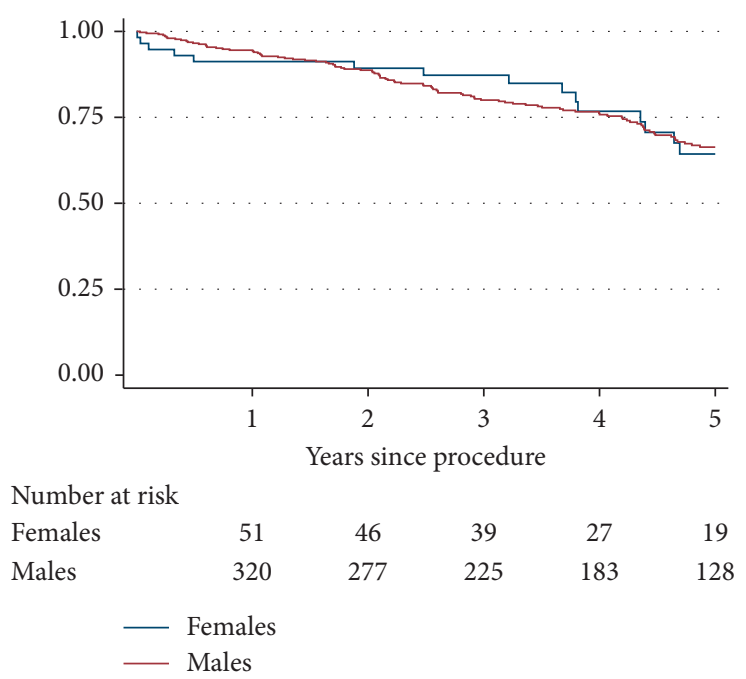

Figure 2: Five-year Kaplan-Meier survival curve by gender.

TABle 4: Multivariable associations between baseline characteristics and 5-year mortality.

\begin{tabular}{|c|c|c|c|c|c|c|}
\hline & \multicolumn{3}{|c|}{ Univariate } & \multicolumn{3}{|c|}{ Multivariable } \\
\hline & OR & $95 \% \mathrm{CI}$ & $p$ value & OR & $95 \%$ CI & $p$ value \\
\hline Sex & 1.03 & $0.53-2.02$ & 0.911 & 1.07 & $0.44-2.94$ & 0.81 \\
\hline Age & & & & 1.09 & $1.05-1.11$ & $<0.001$ \\
\hline ASA physical status $\geq 3$ & & & & 0.63 & $0.28-1.39$ & 0.26 \\
\hline \multicolumn{7}{|l|}{ Comorbidities } \\
\hline Smoking & & & & 1.15 & $0.62-2.37$ & 0.67 \\
\hline Hypertension & & & & 1.27 & $0.63-2.54$ & 0.50 \\
\hline Angina & & & & 0.85 & $0.27-2.20$ & 0.75 \\
\hline Arrhythmia & & & & 1.44 & $0.50-3.15$ & 0.39 \\
\hline Coronary artery disease & & & & 1.12 & $0.54-2.35$ & 0.75 \\
\hline Coronary artery bypass graft & & & & 1.48 & $0.37-4.33$ & 0.50 \\
\hline Myocardial infarction & & & & 0.99 & $0.31-2.34$ & 0.98 \\
\hline Chronic heart failure & & & & 3.23 & $0.87-10.97$ & 0.09 \\
\hline Transient ischaemic attack & & & & 1.35 & $0.32-4.54$ & 0.65 \\
\hline Cerebrovascular accident & & & & 0.85 & $0.24-2.41$ & 0.79 \\
\hline Carotid artery stenting & & & & 1.52 & $0.33-5.23$ & 0.52 \\
\hline Diabetes mellitus & & & & 1.68 & $0.75-3.40$ & 0.16 \\
\hline Hyperlipidaemia & & & & 0.81 & $0.47-1.60$ & 0.49 \\
\hline Peripheral vascular disease & & & & 1.09 & $0.56-2.49$ & 0.82 \\
\hline Chronic kidney disease & & & & 0.76 & $0.25-1.87$ & 0.56 \\
\hline COPD & & & & 1.36 & $0.67-2.59$ & 0.38 \\
\hline Obesity & & & & 0.34 & $0.16-1.1$ & 0.38 \\
\hline \multicolumn{7}{|l|}{ AAA characteristics } \\
\hline Maximum AAA diameter (mm) & & & & 1.01 & $0.98-1.03$ & 0.49 \\
\hline Distal neck diameter $(\mathrm{mm})$ & & & & 0.94 & $0.81-1.09$ & 0.42 \\
\hline Proximal neck diameter (mm) & & & & 1.08 & $0.93-1.28$ & 0.36 \\
\hline Length of infrarenal neck (mm) & & & & 1.01 & $0.98-1.03$ & 0.49 \\
\hline Composite mortality and MAE at 5 years & & & & 1.04 & $0.93-1.18$ & 0.60 \\
\hline
\end{tabular}

Despite female patients undergoing EVAR at an older age than male patients, our study has shown that this has not negatively affected the short- and long-term outcomes after EVAR.

Previous studies have identified that female patients have a more challenging anatomy [20] contributing to longer operative time, increased need for transfusion, and higher rates of complications including endoleak, false aneurysm formation, and wound infection [21]. This, however, is not evident in our study population. Factors such as neck angulation, size of the aneurysm neck, iliac diameter, tortuosity of iliac arteries, and aneurysmal sac diameter at the time of operation were comparable, with no significant differences between sexes identified except for female patients having less intrarenal aortic neck angulation. The congruity in EVAR outcomes in female and male patients could potentially be explained by the homogeneity in baseline anatomical characteristics. Our study thus emphasises the importance of careful selection of patients to 
undergo EVAR not only with regard to anatomical suitability but also to optimising treatment of pre-existing comorbidities to achieve the best outcomes following surgery.

Another factor identified by previous studies, as being of concern, is the rate of undiagnosed comorbid conditions in female patients that then increases operative mortality and morbidity [22]. In our cohort, male patients were more likely than female patients to be past smokers and have a history of CABG; however, both groups had otherwise similar baseline characteristics. In this study, both groups also had no significant differences in technical success, LOS, and postoperative complications in the short- and longer-term period. This perhaps suggests that EVAR, when carried out in a truly elective setting, allows for thorough assessment of preexisting comorbidities and full medical optimisation before the procedure. In addition, the elective nature of surgery allows careful early planning and engagement of other allied health professionals in the recovery period.

Nevertheless, our study has several limitations. As a retrospective, nonrandomised review of a largely prospectively maintained database, there may be a potential selection bias. Although we adjusted our comparison for differences between the two groups, there are still potential confounding factors that were not adjusted, including information regarding medication and surgeon experience. As with previous studies, the female patient in this study are significantly older than the males $(76.8 \pm 9.5$ years in female patient versus $73.5 \pm 9.8$ years in male patient, $p$ value $=0.017)$ and the number of female patients in this study $(n=57)$ may have compromised detection of a significant difference, therefore given rise to the risk for type II error. Nonetheless, our dataset reveals extensive aneurysm-specific anatomy details not previously explored. Since our patients were recruited into this cohort, there has been considerable progress in the stent graft device industry in improving aortic endografts. Hence, modelling studies are needed to assess the effect of newer devices on outcomes and complications between sexes after EVAR.

In conclusion, in our contemporary patient population where the ratio of female to male patients is comparable to previous studies, we have failed to demonstrate differences in early and 5-year outcome after EVAR, mortality, freedom from secondary endovascular procedures, and freedom from MAEs between sexes. As with all EVAR series, long-term follow-up with more patients will determine whether these outcomes remain durable. Thus, EVAR still remains the treatment of choice in both sexes.

\section{Data Availability}

Patient level data used for statistical analysis and to support the findings of this study are available from the corresponding author upon request.

\section{Conflicts of Interest}

The authors declare that there are no conflicts of interest regarding the publication of this paper.

\section{References}

[1] N. N. Abedi, D. L. Davenport, E. Xenos, E. Sorial, D. J. Minion, and E. D. Endean, "Gender and 30-day outcome in patients undergoing endovascular aneurysm repair (EVAR): an analysis using the ACS NSQIP dataset," Journal of Vascular Surgery, vol. 50, no. 3, pp. 486-491, 2009.

[2] J. T. Powell, R. M. Greenhalgh, C. V. Ruckley, and F. G. R. Fowkes, "The UK small aneurysm trial," Annals of the New York Academy of Sciences, vol. 800, no. 1, pp. 249-251, 1996.

[3] H. A. Ashton, M. J. Buxton, H. E. Campbell et al., "Multicentre aneurysm screening study (MASS): cost effectiveness analysis of screening for abdominal aortic aneurysms based on fouryear results from randomised controlled trial," $B M J$, vol. 325, no. 7373, p. 1135, 2002.

[4] P. Ulug, M. J. Sweeting, R. S. von Allmen et al., "Morphological suitability for endovascular repair, non-intervention rates, and operative mortality in women and men assessed for intact abdominal aortic aneurysm repair: systematic reviews with meta-analysis," The Lancet, vol. 389, no. 10088, pp. 2482-2491, 2017.

[5] S. E. Deery, P. A. Soden, S. L. Zettervall et al., "Sex differences in mortality and morbidity following repair of intact abdominal aortic aneurysms," Journal of Vascular Surgery, vol. 65, no. 4, pp. 1006-1013, 2017.

[6] N. Grootenboer, J. L. Bosch, J. M. Hendriks, and M. R. H. M. van Sambeek, "Epidemiology, aetiology, risk of rupture and treatment of abdominal aortic aneurysms: does sex matter?" European Journal of Vascular and Endovascular Surgery, vol. 38, no. 3, pp. 278-284, 2009.

[7] G. Makrygiannis, A. Courtois, P. Drion, J.-O. Defraigne, H. Kuivaniemi, and N. Sakalihasan, "Sex differences in abdominal aortic aneurysm: the role of sex hormones," Annals of Vascular Surgery, vol. 28, no. 8, pp. 1946-1958, 2014.

[8] R. Mofidi, V. J. Goldie, J. Kelman, A. R. W. Dawson, J. A. Murie, and R. T. A. Chalmers, "Influence of sex on expansion rate of abdominal aortic aneurysms," British Journal of Surgery, vol. 94, no. 3, pp. 310-314, 2007.

[9] R. Patel, J. T. Powell, M. J. Sweeting, D. M. Epstein, J. K. Barrett, and R. M. Greenhalgh, "The UK endovascular aneurysm repair (EVAR) randomised controlled trials: longterm follow-up and cost-effectiveness analysis," Health Technology Assessment, vol. 22, no. 5, pp. 1-132, 2018.

[10] M. Desai, E. Choke, R. D. Sayers, M. Nath, and M. J. Bown, "Sex-related trends in mortality after elective abdominal aortic aneurysm surgery between 2002 and 2013 at National Health Service hospitals in England: less benefit for women compared with men," European Heart Journal, vol. 37, no. 46, pp. 3452-3460, 2016.

[11] E. D. Dillavou, S. C. Muluk, and M. S. Makaroun, "A decade of change in abdominal aortic aneurysm repair in the United States: have we improved outcomes equally between men and women?" Journal of Vascular Surgery, vol. 43, no. 2, pp. 230-238, 2006.

[12] K. Ouriel, R. K. Greenberg, D. G. Clair et al., "Endovascular aneurysm repair: gender-specific results," Journal of Vascular Surgery, vol. 38, no. 1, pp. 93-98, 2003.

[13] B. S. Ferket, N. Grootenboer, E. B. Colkesen et al., "Systematic review of guidelines on abdominal aortic aneurysm screening," Journal of Vascular Surgery, vol. 55, no. 5, pp. 1296-1304, 2012.

[14] D. Robinson, B. Mees, H. Verhagen, and J. Chuen, "Aortic aneurysms-screening, surveillance and referral," Australian Family Physician, vol. 42, no. 42, pp. 364-369, 2013. 
[15] N. Grootenboer, M. G. Myriam Hunink, J. M. Hendriks, M. R. H. M. van Sambeek, and J. Buth, "Sex differences in 30day and 5-year outcomes after endovascular repair of abdominal aortic aneurysms in the EUROSTAR study," Journal of Vascular Surgery, vol. 58, no. 1, pp. 42-49, 2013.

[16] P. J. Nordness, G. Carter, B. Tonnessen, W. C. Sternbergh, and S. R. Money, "The effect of gender on early and intermediate results of endovascular aneurysm repair," Annals of Vascular Surgery, vol. 17, no. 6, pp. 615-621, 2003.

[17] M. Mathison, G. J. Becker, B. T. Katzen et al., "The influence of female gender on the outcome of endovascular abdominal aortic aneurysm repair," Journal of Vascular and Interventional Radiology, vol. 12, no. 9, pp. 1047-1051, 2001.

[18] H. Smulyan, R. G. Asmar, A. Rudnicki, G. M. London, and M. E. Safar, "Comparative effects of aging in men and women on the properties of the arterial tree," Journal of the American College of Cardiology, vol. 37, no. 5, pp. 1374-1380, 2001.

[19] P. E. Norman and J. T. Powell, "Abdominal aortic aneurysm," Circulation, vol. 115, no. 22, pp. 2865-2869, 2007.

[20] I. Sinha, B. S. Cho, K. J. Roelofs, J. C. Stanley, P. K. Henke, and G. R. Upchurch, "Female gender attenuates cytokine and chemokine expression and leukocyte recruitment in experimental rodent abdominal aortic aneurysms," Annals of the New York Academy of Sciences, vol. 1085, no. 1, pp. 367-379, 2006.

[21] C. Chung, R. Tadros, M. Torres et al., "Evolution of genderrelated differences in outcomes from two decades of endovascular aneurysm repair," Journal of Vascular Surgery, vol. 61, no. 4, pp. 843-852, 2015.

[22] G. W. Mikkahil, "Coronary heart disease in women," $B M J$, vol. 331, no. 7515, pp. 467-468, 2005. 